\title{
Audit Verbal pada Bidan Penolong Pertama untuk Kasus Kematian Ibu di Kabupaten Bantul 2008
}

\author{
Fihris Hanna ${ }^{1}$, Ircham Mahfoedz ${ }^{2}$, Mulazimah ${ }^{3}$ \\ ${ }^{123}$ Sekolah Tinggi IImu Kesehatan Alma Ata Yogyakarta
}

\begin{abstract}
Abstrak
Peningkatan angka kematian ibu di Kabupaten Bantul dari tahun 2007 berjumlah 6 menjadi 18 pada tahun 2008 merupakan suatu hal yang perlu diketahui penyebabnya. Penelitian kualitatif ini bertujuan untuk mengungkap informasi yang berkaitan dengan : langkah-langkah yang dilakukan bidan dalam menangani kasus kegawatdaruratan obstetri sehubungan dengan terjadinya kenaikan angka kematian ibu di Kabupaten Bantul. Hasil dari penelitian menunjukkan bahwa bidan sebagai penolong pertama dalam melakukan langkah- langkah penanganan kasus kegawatdaruratan obstetri ada yang sudah sesuai dan ada yang belum sesuai dengan standar pelayanan kebidanan dalam penanganan kasus kegawatdaruratan obstetri pada kronologis kematian ibu yang ditanganinya. Simpulan: Berdasarkan hasil penelitian tersebut, menunjukkan bahwa bidan sebagai penolong pertama belum sepenuhnya melakukan tindakan sesuai dengan prosedur, kronologis kematian ibu yaitu seharusnya kematian ibu dapat dicegah pada kedua kasus jika bidan melakukan penapisan kegawatdaruratan obstetri sedini mungkin dan pasien dianjurkan untuk bersalin di rumah sakit.
\end{abstract}

Kata Kunci: audit, verbal, kematian Ibu, bidan penolong pertama

Info Artikel:

Artikel dikirim pada 3 Agustus 2013

Artikel diterima pada 13 September 2013

\section{PENDAHULUAN}

Sampai saat ini angka kematian ibu (AKI) masih merupakan masalah serius yang perlu diperhatikan. Mortalitas dan morbiditas pada wanita hamil dan bersalin adalah suatu masalah besar di negara berkembang. Di Negara miskin, sekitar 25-50\% kematian wanita usia subur disebabkan oleh hal yang berkaitan dengan kehamilan. Kematian saat melahirkan biasanya menjadi faktor utama mortalitas wanita muda pada masa puncak produktivitasnya. Angka kematian ibu (AKI) merupakan barometer pelayanan kesehatan ibu di suatu negara. Bila AKI masih tinggi berarti pelayanan kesehatan ibu belum baik. Sebaliknya bila AKI rendah berarti pelayanan kesehatan ibu sudah baik. Di kawasan ASEAN, Indonesia masih mempunyai AKI yang paling tinggi, menurut data tahun 2007 yaitu sebesar 228/100.000 kelahiran hidup (1).

Menurut data SDKI yang ada, sebenarnya AKI di Indonesia dari tahun ke tahun menunjukkan adanya penurunan jumlah AKI. Dari 390/100.000 kelahiran hidup pada tahun 1994 menjadi 334/100.000 kelahiran hidup pada tahun 1997. Lalu tahun 2003 menjadi 307/100.000 kelahiran hidup, tahun 2005 menjadi 262/100.000 dan pada tahun 2006 menjadi 253/100.000 kelahiran hidup. Terakhir pada tahun 2007 menjadi 228/100.000 kelahiran hidup. Meski telah mengalami penurunan dibandingkan tahun sebelumnya namun hingga saat ini angka kematian ibu (maternal mortality rate atau MMR) di Indonesia masih tertinggi di kawasan Asia Tenggara. Kondisi itu belum merubah status Indonesia sebagai negara dengan angka kematian ibu tertinggi di Asia Tenggara karena angka kematian ibu di negara-negara Asia Tenggara lainnya masih jauh lebih rendah dibandingkan Indonesia.

Sebagian besar penyebab kematian ibu secara langsung (menurut Survei Kesehatan rumah tangga 2001 sebesar $90 \%$ ) adalah komplikasi yang terjadi pada saat persalinan dan segara setelah bersalin. Penyebab tersebut dikenal dengan Trias Klasik yaitu perdarahan (28\%), eklampsia (24\%) dan infeksi (11\%). Sedangkan penyebab tidak langsungnya antara lain adalah ibu hamil menderita Kurang Energi Kronis (KEK) $37 \%$, anemia (Hb kurang dari $11 \mathrm{gr} \%$ ) 40\%. Kejadian 
anemia pada ibu hamil ini akan meningkatkan risiko terjadinya kematian ibu dibandingkan dengan ibu yang tidak anemia (2).

Kehamilan risiko tinggi juga dapat meningkatkan risiko saat persalinan. Yang termasuk kehamilan dengan risiko tinggi antara lain, tinggi badan kurang dari 145 $\mathrm{cm}$, riwayat kehamilan yang buruk ( pernah keguguran, pernah persalinan prematur, riwayat persalinan dengan tindakan ekstraksi vakum, ekstraksi forsep, operasi Sectio caesaria ), pre eklampsia, eklamsia, gravida serotinus, kehamilan dengan perdarahan anterpartum, kehamilan dengan kelainan letak.

Angka kematian ibu melahirkan di Kabupaten Bantul selama tahun 2008 mengalami kenaikan yang cukup tajam. Artinya, selama ini sistem pembangunan kesehatan atau penanganan ibu melahirkan di kabupaten itu ada kesalahan. Buktinya persoalan kesehatan khususnya jumlah ibu melahirkan meninggal mengalami kenaikan sangat tajam. Pada tahun 2007 tercatat angka ibu melahirkan meninggal, jumlahnya mencapai 6 kasus. Sedangkan pada tahun 2008 naik menjadi 18 kasus. Selama Januari hingga April 2008, ada 7 orang ibu hamil yang meningggal dunia. Menurut profil Dinkes Bantul penyebab kematian ibu beragam, ada yang meninggal karena TBC, keracunan kehamilan, pembesaran jantung, emboli air ketuban, perdarahan. Sedangkan menurut survei awal yang dilakukan dengan datang ke Dinas Kesehatan Kabupaten Bantul dan bertanya ke bagian pelayanan kesehatan, di dapatkan data selama tahun 2008 terdapat 18 kasus kematian ibu di kabupaten bantul dengan penyebabnya antara lain: TBC, eklampsi, pembesaran jantung (cardiomegaly), perdarahan, emboli air ketuban, gagal jantung (decompensasi cordis), sepsis, pneumonia, atonia uteri, oedem paru oleh karena pre eklampsi berat, vagal reflek, encephalophaty oleh karena bilirubinemia (3).

Peranan bidan dalam masyarakat sebagai tenaga kesehatan terlatih pada Sistem Kesehatan Nasional adalah sebagai berikut: memberikan pelayanan sebagai tenaga terlatih, meningkatkan pengetahuan kesehatan masyarakat, meningkatkan penerimaan keluarga berencana, memberikan pendidikan pada "dukun beranak", meningkatkan sistem rujukan. Pelayanan kesehatan yang patut dilaksanakan oleh bidan adalah: meningkatkan upaya pengawasan ibu hamil, meningkatkan gizi ibu hamil dan menyusui, meningkatkan peranan gerakan $\mathrm{KB}$, meningkatkan sistem rujukan, meningkatkan penerimaan imunisasi ibu hamil dan bayi. Selain itu bidan juga melakukan pengawasan kehamilan dan menetapkan: kehamilan, persalinan, dan postpartum dengan risiko tinggi; kehamilan, persalinan, dan postpartum yang meragukan; kehamilan, persalinan, dan postpartum dengan risiko rendah. Berdasarkan hal tersebut, maka bidan sebagai tenaga kesehatan terlatih yang menjadi ujung tombak pelayanan kesehatan dan melayani masyarakat melalui BPS (Bidan Praktek Swasta), POLINDES (Pondok Bersalin Desa), dll, mempunyai kewenangan untuk menangani kasus obstetri di masyarakat dan melakukan rujukan untuk kasus kegawatdaruratan obstetri, sehingga hal ini merupakan salah satu upaya untuk mencegah kematian ibu dan akhirnya dapat menurunkan angka kematian ibu (4).

\section{BAHAN DAN METODE}

Jenis penelitian ini adalah penelitian kualitatif. Penelitian kualitatif merupakan suatu paradigma penelitian untuk mendeskripsikan peristiwa, perilaku orang atau suatu keadaan pada tempat tertentu secara rincidan mendalam dalam bentuk narasi ${ }^{5}$.Populasi penelitian adalah jumlah bidan yang menangani kasus kegawatdaruratan obstetri di Kabupaten Bantul pada tahun 2008. Sampel pada penelitian ini sejumlah 2 orang bidan yang memenuhi kriteria yaitu mempunyai kasus rujukan kegawatdaruratan obstetri ke rumah sakit dan akhirnya pasien meninggal dunia di rumah sakit. Penelitian ini dilaksanakan di wilayah kabupaten bantul tepatnya di klinik kebidanan yang mempunyai kasus kegawatdaruratan yang akhirnya dirujuk ke rumah sakit dan akhirnya pasien meninggal dunia di rumah sakit. Penelitian dilakukan di 2 tempat yaitu di BPS Endang Purwaningsih Kedaton Pleret Bantul dan di BPRB Wikaden Siluk II Selopamioro Imogiri Bantul pada bulan agustus 2009. Data yang akan dikumpulkan pada penelitian ini adalah data primer yang dikumpulkan dengan menggunakan wawancara yang dipandu dengan panduan wawancara dengan pertanyaan yang bersifat terbuka pada responden.

\section{HASIL DAN BAHASAN}

\section{Hasil Penelitian}

1. Karakteristik Responden

Karakteristik responden dalam penelitian ini meliputi umur bidan, pendidikan terakhir bidan, lama masa kerja dan tempat pelayanan kesehatan yang dipunyai bidan serta kasus kegawatdaruratan yang dirujuk oleh bidan ke rumah sakit.

Pengalaman responden tentang pengungkapan kasus kematian ibu beragam, ada yang sama dan tidak. Berikut ini diuraikan pengalaman bidan :

a. Pengungkapan tentang identitas kasus

1) Pengungkapan diagnosa kasus pasien Pasien yang ditangani responden kebetulan diagnosa awalnya sama 
Tabel 1. Karakteristik Responden

\begin{tabular}{cclll}
\hline $\begin{array}{c}\text { No } \\
\text { Responden }\end{array}$ & Umur & $\begin{array}{c}\text { Pendidikan } \\
\text { Terakhir }\end{array}$ & Lama masa kerja & Tempat pelayanan kesehatan yang dipunyai \\
\hline R1 & 34 th & DIII & \pm 12 tahun & BPS (Bidan Praktek Swasta) \\
R2 & 49th & DI & \pm 25 tahun & BPRB (Balai Pengobatan dan Rumah Bersalin) \\
\hline
\end{tabular}

Sumber: Data Primer 2009

“... Pasien datang dalam keadaan Inpartu, pembukaan $1 \mathrm{~cm}$ (kala 1 fase laten)" (R1,R2)

2) Pengungkapan Tindakan selanjutnya yang dilakukan bidan untuk menangani kasus Tindakan pertama yang dilakukan oleh responden ketika pasien datang juga sama,mereka melakukan tindakan sesuai prosedur

“... ya sesuai prosedur..melakukan anamnesa, melakukan pemeriksaan fisik, pemeriksaan dalam, observasi HIS dan DJJ"

(R1, R2).

b. Pengungkapan tentang kajian riwayat pasien

1) Pengungkapan Kajian riwayat pasien di tempat bidan

Kajian riwayat pasien antara kedua responden bervariasi, dari keluhan dan riwayat kesehatan

“...pasien saya itu riwayat obstetriknya G4 $P 2 A b 1$, tapi dia rajin melakukan ANC di BPS dan Puskesmas, tidak ada keluhan selama kehamilan dan pasien tidak menderita penyakit menular atau menurun" (R1)

“...dia riwayatnya $G 1 P O A b$ datang mengeluh kenceng-kenceng belum teratur, dari rekam medik saya dulu trimester 1 pasien mengeluh mual, pusing dan telat menstruasi; pada trimester II tidak ada keluhan; pada trimester III pasien mengeluh batuk; tidak ada riwayat penyakit menular atau menurun" (R2)

c. Pengungkapan tentang kronologis kematian ibu yang kasusnya ditangani oleh bidan

1) Pengungkapan kronologi kematian ibu oleh bidan

Kronologi kematian pasien yang dipaparkan responden juga bervariasi,responden pertama mengatakan kematian pasien dikarenakan 'emboli air ketuban'karena ketika akan dilakukan pemeriksaan dalam tiba-tiba pasien sesak nafas, mulutnya mecucu seperti mulut ikan, diberikan oksigen lalu dirujuk. . Sampai di Rumah Sakit pasien diberi RJP tetapi tidak tertolong (meninggal).Bayi juga ikut meninggal.

“...pasien saya itu datang lalu saya periksa, dianamnesa\&pemeriksaan fisik, lalu periksa dalam ternyata baru pembukaan 1,tak suruh tinggal di tempat saya aja,karena sdh G4,terus \pm 7 jam kemudian ketuban pecah, mau tak periksa dalam tiba-tiba pasien sesak nafas, mulutnya mecucu seperti mulut ikan terus tak kasih oksigen, lalu tak dirujuk ke Rumah Sakit Permata Husada, kira-kira jarak rujukan $\pm 1 / 2 \mathrm{~km}$ ditempuh dalam waktu 5 menit. Selama perjalanan pasien tetap diberikan oksigen dan saya damping dg keluarga pasien. Sampai di Rumah Sakit pasien diberi RJP tetapi tidak tertolong. Bayi juga ikut meninggal." (R1)

Responden kedua mengungkapkan penyebab kematian ibu karena 'vagal reflek'

“... Pasien G1 datang ke saya dg keluhan kenceng-kenceng belum teratur pada tanggal 17 Oktober 2008 jam 20.00 WIB,tak periksa TTV dan fisik hasilnya ini (memperlihatkan buku rekam medik): TD: 130/80 $\mathrm{mmHg}, \mathrm{N}: 84 \mathrm{x} /$ menit, R: $24 \mathrm{x} /$ menit, $\mathrm{S}: 36,5^{\circ} \mathrm{C}$. pada palpasi : TFU = $32 \mathrm{~cm}$, presentasi kepala, punggung kiri. Pemeriksaan dalam hasilnya $=\mathrm{V} / \mathrm{U}$ tenang, portio tebal lunak, pembukaan $1 \mathrm{~cm}$, selaput ketuban (selket) positif $(+)$, sarung tangan lendir darah (STLD) (+)/positif, lalu dilakukan observasi HIS dan DJJ.

Tanggal 18 Oktober 2008 jam 09.00 WIB hasil observasi : TD 120/80 mmHg. HIS 3 x / 10' / 40"/ sedang. DJJ +, 138x/menit. Pada pemeriksaan dalam hasilnya: V/U tenang, parsio lunak, pembukaan $5 \mathrm{~cm}$, selaput ketuban (selket) positif $(+)$, kepala masih tinggi. “... Diagnosa saya Partus tak maju,terus keluarganya saya beri penjelasan,mereka berunding dan memutuskan minta dirujuk ke 'RSPS' Bantul dengan alasan mempunyai JAMKESMAS. Ketika saya rujuk keadaan umum pasien baik. Saya juga ikut 
merujuk bersama keluarganya, Sampai di RSPS pasien di induksi sampai habis 1 plabot, lalu di observasi pembukaan tetap $5 \mathrm{~cm}$. kemudian diteruskan plabot ke dua dan pembukaan hanya bertambah $2 \mathrm{~cm}$, menjadi $7 \mathrm{~cm}$ dan kepala janin masih tinggi. Lalu disiapkan operasi SC emergency karena janin mengalami fetal disstres. Tapi Keadaan umum ibu hamil jelek ketika dilakukan pembedahan. Setelah operasi keadaan umum ibu bertambah jelek dan akhirnya dirawat di ruang ICU dan akhirnya meninggal dengan diagnosa akhir yaitu Vagal Reflek."(R2)

d. Pengungkapan tentang mekanisme yang dilakukan bidan untuk ikut serta mencegah angka kematian ibu

Dalam hal ini kedua responden saya mengatakan hal yang sama

“... biar AKI tidak tambah banyak ya melakukan pertolongan persalinan sesuai dengan asuhan persalinan"

normal, konsultasi kepada dokter spesialis kandungan jika ada kegawatdaruratan, melakukan tindakan sesuai dengan protap kegawatdaruratan, menyiapkan fasilitas mobil rujukan, untuk mobil rujukan Alhamdulillah saya ada sendiri,jadi tidak perlu menunggu ambulance dari rumah sakit." (R1)

“... peran saya sebagai bidan untuk ikut mengurangi AKI misalnya melakukan pertolongan persalinan sesuai dengan asuhan persalinan normal, konsultasi kepada dokter spesialis kandungan jika ada kegawatdaruratan, melakukan tindakan sesuai dengan protap kegawatdaruratan, menyiapkan fasilitas mobil rujukan,mobil rujukannya saya juga ada." (R2)

e. Pengungkapan tentang Langkah-langkah yang dilakukan bidan untuk mengani kegawatdaruratan

Dalam hal ini kedua responden saya juga mengatakan hal yang sama

“... kalau ada kasus gawat darurat ya saya harus segera bertindak tentu saja sesuai kasus\&kewenangan saya,kalu sudah bukan kewenangan saya tentu saja tak rujuk ke rumah sakit." (R1)

“... langkah saya tentu langsung melakukan tindakan yang sesuai, dan kalau kasusnya sudah bukan kewenangan saya langsung tak rujuk ke rumah sakit." (R2)

\section{Pembahasan}

1. Langkah-langkah yang Dilakukan Bidan sebagai Penolong Pertama dalam Menangani Kasus Kegawatdaruratan Obstetri.

Hasil penelitian menunjukkan bahwa bidan sebagai penolong pertama selalu melakukan kolaborasi dengan dokter spesialis kandungan dalam menangani kasus kegawatdaruratan obstetri.Hal ini sesuai dengan teori dari Manuaba (2003), yang mengatakan bahwa salah satu peranan bidan sebagai tenaga kesehatan terlatih di masyarakat adalah meningkatkan sistem rujukan untuk kasus kegawatdaruratan obstetri. Namun rujukan yang dilakukan bidan sepertinya mengalami keterlambatan, pada kasus pertama misalnya jika dilihat dari status pasien yang multiparitas dan pernah mengalami keguguran yaitu G4P2A1 (hamil ke 4, pernah melahirkan anak hidup 2 kali, dan mengalami keguguran 1 kali), serta jarak kehamilan kurang dari 2 tahun (pada bulan maret tahun 2007 pasien mengalami keguguran dan bulan juni 2007 kemudian pasien hamil lagi), hal ini merupakan kehamilan yang mempunyai faktor risiko dan risiko tinggi. Dilihat dari status dan riwayat kehamilan yang beresiko tersebut, seharusnya bidan tidak menangani sendiri di klinik yang dimilikinya, tetapi harus dilakukan konseling sejak kehamilan pasien bahwa kehamilannya merupakan kehamilan yang beresiko dan pasien dianjurkan untuk sebaiknya melahirkan di fasilitas pelayanan kesehatan yang komperehensif seperti rumah sakit sehingga dapat segera mendapat penanganan yang cepat jika terjadi kegawatdaruratan obstetri.

2. Kronologis Kematian Ibu di Kabupaten Bantul Pada Tahun 2008 dari Sudut Pandang Bidan sebagai Penolong Pertama

Dari hasil penelitian menunjukkan bahwa ketika pasien datang ke tempat bidan dengan keadaan umum baik, telah dilakukan anamnesis, pemeriksaan fisik dan pemeriksaan dalam, observasi HIS dan DJJ sesuai dengan prosedur. Kemudian setelah terjadi kegawatdaruratan bidan telah melakukan tindakan sesuai kasus yang ditangani. Antara lain pada responden pertama ketika ketuban pecah spontan dan akan dilakukan pemeriksaan dalam tiba-tiba pasien mengalami sesak nafas, oleh bidan segera diberikan oksigenasi dan dirujuk ke rumah sakit terdekat. Jarak antara rumah bidan dengan rumah sakit ditempuh dalam waktu \pm 5 menit.Bidan melakukan pendampingan ketika merujuk pasien. Ketika diperjalanan bidan tetap memberikan 
oksigen kepada pasien hingga sampai di rumah sakit. Kemudian di rumah sakit pasien diberikan RJP tetapi tidak tertolong karena emboli air ketuban menyebabkan kematian yang sangat cepat. Hal ini sesuai dengan teori dari Sarwono (2007) yang menjelaskan bahwa jika terjadi emboli, air ketuban dengan mekonium, rambut lanugo dan vernik kaseosa masuk kedalam sinussinus dalam dinding uterus dan dibawa ke paruparu sehingga menyebabkan sesak nafas dan mengakibatkan pasien meninggal dunia. Pada syok karena emboli air ketuban sering ditemukan gangguan pembekuan darah.

Sedangkan pada kasus yang ditangani oleh responden kedua, pasien datang dengan keadaan umum baik, telah dilakukan anamnesis pemeriksaan fisik dan pemeriksaan dalam, observasi HIS dan DJJ.Observasi dilakukan mulai pasien datang yaitu tgl 17-10-08 jam 20.00 WIB sampai tgl 18-10-08 pkl 09.00 WIB hingga ditemukan hasil pemeriksaan yaitu pembukaan servik $5 \mathrm{~cm}$ tetapi kepala masih tinggi, seharusnya pada keadaan ini pasien harus dirujuk, tetapi oleh bidan masih diobservasi hingga 4 jam kemudian yaitu pkl 13.00 WIB. Hal ini seharusnya tidak boleh dilakukan, karena menurut teori asuhan persalinan normal salah satu kriteria kegawatdaruratan ibu yang harus segera dirujuk adalah pada primipara dalam fase aktif kala I persalinan dan kepala janin masih $5 / 5$ (kepala masih tinggi). Hal ini harus segera dilakukan dengan alasan pada kala I persalinan, kepala seharusnya sudah masuk ke dalam rongga panggul.Bila ternyata kepala memang tidak dapat turun, mungkin bagian terbawah janin (kepala) terlalu besar dibandingkan dengan diameter pintu atas pangggul.Mengingat bahwa hal ini patut diduga sebagai disproporsi kepala panggul (CPD) maka sebaiknya ibu dapat melahirkan di fasilitas kesehatan yang mempunyai kemampuan untuk melakukan operasi seksio sesaria sebagai antisipasi apabila terjadi persalinan macet (disproporsi). Penyulit lain dari posisi kepala diatas pintu panggul adalah tali pusat menumbung yang disebabkan oleh pecahnya selaput ketuban yang disertai turunnya tali pusat (APN, 2007:43). Tetapi pada kasus yang ditangani oleh responden ke 2 pasien baru dirujuk setelah diketahui terjadi keadaan partus tak maju pada pkl 13.00 WIB, bidan segera memberitahukan kepada keluarga pasien. Kemudian setelah berunding keluarga pasien minta untuk dirujuk ke rumah sakit.Pada waktu merujuk bidan juga mendampingi pasien. Di rumah sakit pasien diberikan tindakan induksi sampai habis 2 plabot infus tetapi induksi gagal karena pembukaan dari $5 \mathrm{~cm}$ hanya menjadi $7 \mathrm{~cm}$, kaena setelah itu diketahui bahwa janin mengalami fetal distress maka segera disiapkan operasi section caesaria emergency. Ketika diruang operasi keadaan umum ibu menjadi jelek tetapi operasi tetap berjalan sampai akhirnya bayi lahir.Pasca operasi keadaan umum ibu bertambah jelek sehingga harus dirawat intensif di ruang ICU tetapi akhirnya ibu meninggal. Beberapa jam kemudian bayinya juga ikut meninggal.

3. Penyebab-penyebab Kematian Ibu Pada Kasus yang Ditangani Bidan sebagai Penolong Pertama

Pada kasus pertama merupakan kasus yang berpotensi menyebabkan kegawatdaruratan yaitu terjadinya emboli air ketuban yang menyebabkan kematian pada multiparitas dan jarak kehamilan $<2$ tahun. Hal ini sesuai dengan teori dari Hanafi (2004:23) bahwa kehamilan dengan kurang dari 2 tahun merupakan kehamilan risiko tinggi dan harus mendapatkan penanganan khusus. Sedangkan pada kasus kedua kemungkinan terjadi DKP (Disproporsi Kepala Panggul), tetapi masih diobservasi di tempat bidan sampai kurang lebih 17 jam yang menyebabkan terjadi keterlambatan merujuk dan terlambat mendapat penanganan yang sesuai di tempat rujukan sehingga menyebabkan keadaan umum pasien memburuk dan akhirnya meninggal dunia.

4. Mekanisme yang Ditempuh Bidan sebagai Tenaga Kesehatan Terlatih Dilini Terdepan untuk Ikut anDil dalam Upaya Pencegahan Angka Kematian Ibu.

Dari hasil wawancara yang dilakukan kepada bidan langkah-langkah yang ditempuh adalah: pertolongan persalinan sesuai asuhan persalinan normal, konsultasi jika ada kegawatdaruratan obstetri, melakukan tindakan sesuai dengan prosedur, menyiapkan fasilitas mobil rujukan sewaktu-waktu dibutuhkan. Hal ini sesuai dengan teori dari Manuaba (2003), yang mengatakan bahwa salah satu peranan bidan sebagai tenaga kesehatan terlatih di masyarakat adalah meningkatkan.

\section{SIMPULAN DAN SARAN}

Berdasarkan hasil penelitian dan pembahasan yang telah dilakukan dapat disimpulkan sebagai berikut:

1. Langkah-langkah yang dilakukan bidan dalam menangani kasus kegawatdaruratan obstetri adalah: Pada responden pertama Bidan 
menangani kasus faktor risiko obstetri dan pada responden ke dua bidan menolong kasus patologi. Seharusnya ke dua kasus ini di rujuk ke rumah sakit sedini mungkin agar mendapat penanganan yang komperehensif dan dapat mencegah terjadinya kematian ibu.

2. Kronologis kematian ibu yang bermula dari rujukan klinik pelayanan kesehatan di Kabupaten Bantul pada tahun 2008 dari sudut pandang bidan sebagai penolong pertama sehubungan dengan terjadinya kenaikan angka kematian ibu dan kaitannya dengan peran bidan terhadap pencegahan angka kematian ibu adalah: Pada kasus pertama, paritas (jumlah anak) yang lebih dari 3 dan riwayat obstetri pernah mengalami abortus (keguguran) serta jarak kehamilan yang terlalu dekat yaitu kurang dari 2 tahun merupakan potensi terjadi kegawatdaruratan obstetri dan berkontribusi terhadap terjadinya emboli air ketuban yang menyebabkan kematian ibu. Seharusnya jika diketahui terdapat faktor risiko pada pasien bidan harus menyarankan agar pasien merencanakan persalinan di rumah sakit agar segera mendapat penanganan yang cepat jika terjadi masalah kagawatdaruratan dan mencegah terjadinya kematian ibu. Sedangkan pada kasus ke dua merupakan kasus patologi obstetri yaitu pada kala I fase aktif dan kepala janin belum masuk pangggul seharusnya bidan langsung merujuk pasien ke rumah sakit. Tetapi pada kasus ini masih diobservasi di klinik bidan sampai kurang lebih 17 jam. Bahkan sejak masa antenatal care pada umur kehamilan $>36$ minggu dan diketahui bahwa kepala belum masuk panggul sebenarnya harus sudah direncakan untuk melakukan pertolongan persalinan di rumah sakit.

3. Penyebab-penyebab kematian ibu pada kasus yang ditangani bidan sebagai penolong pertama adalah: Pada kasus pertama merupakan kasus yang berpotensi menyebabkan kegawatdaruratan yaitu terjadinya emboli air ketuban yang menyebabkan kematian pada multiparitas dan jarak kehamilan $<2$ tahun. Sedangkan pada kasus kedua kemungkinan terjadi DKP (Disproporsi Kepala Panggul), tetapi masih diobservasi di tempat bidan sampai kuran lebih 17 jam sehingga terjadi ketrlambatan merujuk dan terlambat mendapat penanganan yang sesuai di tempat rujukan.

4. mekanisme yang ditempuh bidan sebagai tenaga kesehatan terlatih di lini terdepan untuk ikut andil dalam upaya pencegahan angka kematian ibu antara lain:

a. Mekanisme yang sesuai dengan standar prosedur pelayanan kebidanan:

1) Melakukan anamnesa ketika pasien datang

2) Melakukan pemeriksaan fisik, vital sign, pemeriksaan dalam setiap 4 jam sekali, mendokumentasikan dalam partograf, memberikan Oksigenasi ketika pasien sesak napas pada pasien dengan emboli air ketuban, merujuk pasien disertai pendampingan ke rumah sakit.

b. Mekanismeyang kurang sesuai dengan standar prosedur pelayanan kegawatdaruratan:

Pada kasus pertama ketika bidan mengetahui ada pasien dengan faktor risiko seperti multiparitas, mempunyai riwayat keguguran, dan jarak kehamilan yang terlalu dekat (kurang dari 2 tahun), seharusnya setelah mengetahui hal-hal tersebut bidan menyarankan agar pasien melakukan pertolongan persalinan di rumah sakit atau jangan ditangani di rumah bidan.

Pada kasus kedua seharusnya dilakukan rujukan berencana saat antenatal care, jika pada primigravida umur kehamilan $>36$ minggu dan kepala janin belum masuk panggul.

Tetapi pada kasus ini sampai masuk kala I fase aktif kepala belum masuk panggul tetap diobservasi di tempat bidan.

\section{RUJUKAN}

1. Sarwono. 2000. Buku Acuan Nasional Pelayanan Kesehatan Maternal Neonatal. Yayasan Bina Pustaka: Jakarta.

2. Manuba. 2003. Ilmu Kesehatan Kebidanan, Penyakit Kandungan dan Keluarga Berencana Untuk Pendidikan Bidan. EGC: Jakarta

3. Dinas Kesehatan Kabupaten Bantul, 2008. Profil Kesehatan Kabupaten Bantul, Dinkes Kab. Bantul, Yogyakarta.

4. Manuba. 2003. Ilmu Kesehatan Kebidanan, Penyakit Kandungan dan Keluarga Berencana Untuk Pendidikan Bidan. EGC: Jakarta

5. Satori, Djam'an. 2009. Metodologi Penelitian Kualitatif. Alfabeta: Bandung.

6. Moleong. 2004. Metodologi Penelitian Kualitatif. PT Remaja Rosda Karya: Bandung. 